as compared to the natives of the densely populated parts of Furope and Asia, have undergone little evolution against consumption. As a consequence no African colony has ever succeeded in Earope or Asia. For instance, the Dutch and English imported about 15,000 negroes into Ceylon a century ago. Within 20 years all, except a mere handful, had perishe 1 mainly of consumption and that is a country where the disease is not nearly so prevalent as in Northern Europe or the more settled parts of Northern Asia.

There can be little doubt that the sterility of New World races when brought in contact with civilisation is due mainly to ill health. The sterility of our upper classes, as any medical man will inform $\mathrm{Mr}$. Galton, is mainly voluntary. It is due to the possession of special knowledge. The growing sterility of the lower orders is due to the spread of that knowledge; hence the general and continuous fall in the birth-rate. Until we are able to estimate the part played by this knowledge it would be vain to collect statistics of comparative fertility. We have frequently been told that no city family can persist for four generations unless fortified by cunntry blood. That, I believe, is a complete error. Country blood does not strengthen city blood. It weakens it ; for it has been less thoroughly purged of weak elements. It is true, owing to the large mortality in cities and the great immigration from the country, it is difficult to find a city family which has had no infusion of country blood for four generations. But to suppose on that account that country blood strengthens city blood against the special conditions of city life is to confuse post hoo with propter hoo. Slum life and the other evil influences of civilisation, including bad and insufficient food, vitiated air, and zymotic diseases, injure the individual. They make him acquire a bad set of traits. But they do not injure the hereditary tendencies of the race. Had they done so, civilisation, which implies a dense population, would have been impossible. $\mathrm{Oa}$ the contrary, by weeding out the unfittest they make the race strong against those influences. If, then, we wish to raise the standard of our race we must do it in two ways. In the first place, we must improve the conditions under which the individual develops and so make him a finer animal. In the second place, we must endeavour to restrict as much as possible the marriage of the physically and mentally unfit. In other words, we must attend both to acquired and inborn characters. By merely improving the conditions under which people live we shall improve the individual but not the race. The same measures will not achieve both objects. Medical men have done a good deal for the improvement of the acquired characters of the individual by improving sanitation. They have done nothing towards the second object, the improvement of the inborn traits of the race. Nor will they do anything until they have acquired a precise knowledge of heredity from biologists. On the other hand, before biologists are able to influence medical men they must bring to bear their exact methods of thought on the great changes produced in various races by the experience during thousands of years of disease. I am sure our knowledge of beredity will gain in precision and breadth by a consideration of these tremendous, long-continued and drastic experiments conducted with such momentous results by nature. No experiments conducted by man can compare with them in magnitude and completeness. As I have already intimated, the precise statistical information on which our conclusions may be based are already collected and tabulated. I am sure it is good neither for medicine nor biology that medical men and biologists should live in separate and closed compartments, each body ignoring the splendid mass of data collected by the other. Much of medicine should be a part of biology and much of biology a part of medicine.

I am, Sirs, yours faithfully,

Southsea, May 30th, 1904.

G. ARCHDALL ReID.

\section{ABSCESS OF THE FRONTAL SINUS.}

To the Editors of THE LANCET.

SIRS,-I read with much interest Mr. Herbert Tilley's article in THE LANCET of May 21st, 1904, p. 1414, on Some Experiences in the Surgical Treatment of Suppurative Lesions of the Nasal Accessory Sinuses; also I had previously read with interest his article in THE LANCET of July 14th, 1900, p. 100, on Empyema of the Frontal Sinus; but I should like to draw his attention to two short but admirable papers by $\mathrm{Mr}$. Charles Higgens on Distension of the Frontal Sinus in the Guy's Hospital Reports for 1880-81 and 1893. In the earlier paper Mr. Higgens describes with admirable lucidity a small round flactuating swelling which forms when the bone has become absorbed in cases of long. standing distension of the frontal sinus at the inner angle of the orbit and which resembles a distended laorymal sac, but is situated above the tendo oculi instead of below it and which cannot, like the distende 1 sac, be emptied by pressure nor can any of its contents be squeezed through the canaliculi. It also has one marked peculiarity-it varies in size at different times in the day.

I have recently seen a case where this swelling was very noticeable This swelling only occurs in cases where the bone has become absorbed and the contents of the sinus project through a hole in the bone beneath the integuments. When present this swelling is of the greatest importance both for diagnosis and treatment. In one of Mr. Higgens's cases "an exploratory incision showed the swelling to be a distended frontal sinus containing white viscid mucus. A probe could be pushed into the cavity a distance of three inches ; its breadth appeared to be about one inch."

With regard to treatment, when this swelling is present all that is necessary to do is to make an incision through the swelling and pass a drainage tube into the cavity of the nose. There is obviously in this operation no danger to life, whereas if the trephine is used the freshly cut surface of the diploë is liable to absorb septic material and consequently occur osteomyelıtis, meningitis, and death. Mr. Higgens has known all about this small swelling for a quarter of a century, but notwithstanding his two papers in the Guy's Hospital Reports even the greatest nasal specialists seem still to be entirely ignorant as to its nature, nor can I find anything about it in any book.

With regard to the treatment after opening the frontal sinus I fully agree with $\mathrm{Mr}$. Tilley that "from the moment the operation is completed the motto of the surgeon must be, 'Free, unhindered, spontaneous drainage,' and if he secures this he need never fear that any serious harm may come to his patient." I entirely fail, however, to see the desirability of the complete obliteration of the frontal sinus which Mr. Tilley recommends. It is naturally a cavity and I think should remain so if free drainage is secured.

I am, Sirs, yours faithfully,

Beckenham, May 31st, $1904 . \quad$ RobERT S. WAINEWRIGHT.

\section{THE INFECTIVITY OF SCARLET FEVER.}

\section{To the Editors of THE LANCET.}

SIRS, - The above subject having lately been much under discussion, the following, taken from the Medical World of Philadelphia for February, 1902, may be of interest :-

"In the spring of 1900 a family of children had scarlet fever and though very severe none of them died. During the desquamation whole casts of fingers and toes came away. The mother collected a quantity of these and placed them in a pasteboard box. Having moved to my neighbour hood they were visited in February, 1901, by a family consisting of father, mother, and boy, three years of age. The conversation turning upon scarlet fever the hostess bronght out her box of "relics" and exhibited the contents to her visitors, making a special display for the benefit of the boy. ...... On the fourth day following the child had a chill, developing into a very malignant type of scarlet fever. A sister of the child's mother visited the patient from the second to the fifth day with her three children; also the father's brother visited the boy on the third day with his four yearold boy. The visiting families lived 15 miles away. ...... No other children in the community were exposed and no others had the disease, while everyone that was exposed had scarlet fever in its worst form and every one of them died." The above was reported by Dr. W. R. Fowler of Pottsville, Texas. I am, Sirs, yours faithfully,

Sierre Madre, California. ARTHUR E. Gresham, M.D.

\section{EXTRAORDINARY CASE OF SUICIDAL CUT-THROAT.}

\section{To the Editors of THE LANOET,}

SIRS, - The extraordinary features of a case of suicidal cut-throat perhaps merit my encroaching on your valuable space. On June 2 nd at 8.30 A M. I received an urgent call to a man who had attempted suicide by cutting his 